in the mental state. It is pointed out that the method is simple, inexpensive, not dangerous, and not contra-indicated by tubercle or feeble health; that it seldom causes alarming pyrexia, but that, like all methods of protein shock, it is inconstant in its results.

S. M. Coleman.

Presentation of General Paralytics Successfully Treated by Sodium Stovarsol. (Soc. Clin. de Méd. Ment., November, I929.) Marchand, $L$.

Twelve women were treated by three series of twenty intramuscular injections of $1 \mathrm{grm}$. of sodium stovarsol, three injections being given each week, with a rest period of one month between each series. Six of the cases are reported to be in a state of remission; two have resumed their normal occupation. One case is still under treatment, but shows improvement, while another has shown some decrease in affective unbalance. In the other four cases the treatment has been without effect. In all the improved cases there has been some modification in the reactions of the cerebro-spinal fluid, but there was no change in the blood Wassermann and Meinicke. The paper is followed by a discussion disclosing a marked diversity of opinion as to the relative merits of malarial, tryparsamide and stovarsol therapy.

S. M. Coleman.

The Use of Sulphur for the Production of Fever. (Arch. of Neur. and Psychiat., Fuly, 1931.) Mackay, P.P.

The author carried out experimental work on rabbits with injections of sulphur in oil. He thinks that the fever is due to the liberation of protein from necrosed muscle, the destruction of the muscle being due either to the sulphur or to the liberation of hydrogen sulphide. Sulphur is superior to typhoid vaccinc, in that the fever is of longer duration and that chill is usually avoided, but inferior in that local pain and tenderness may be very troublesome. It has several advantages over malaria, and is easier to control.

G. W. T. H. Fleming.

\title{
4. Neurology.
}

A Clinical Contribution to the Study of Cerebral Tumours. (Rassegna di Studi Psichiatrici, May-Fune, 1930.) Antonini, G.

The author gives a detailed account of twenty cases of cerebral tumour varying in type and situation, to which he adds a description of the post-mortem findings. He analyses systematically the physical signs and symptoms, and the results of chemical and radiological examinations. In discussing the symptoms in general, he lays stress upon the frequency and earliness of headache, which he attributes to the early stages of hypertension in the cerebro-spinal fluid. He pays special attention to mental symptoms, describing in detail the general picture, and analysing the localizing value of certain groups of symptoms.

He distinguishes carefully between symptoms which constitute 